\title{
ISOLATION OF STEM CELLS FROM THE MID GUT EPITHELIUM OF CULEX PIPIENS MOSQUITOES (DIPTERA: CULICIDAE)
} By

\author{
N. M. WASSIM ${ }^{1}$, B. A. SOLIMAN ${ }^{1}$, M. I. HUSSEIN ${ }^{1}$ AND H. G. METWALY ${ }^{2}$
}

Molecular Biology Unit, Faculty of Science, Suez University, Suez ${ }^{1}$, and Department of Hematology and Immunology, Faculty of Medicine, Cairo University, Cairo ${ }^{2}$, Egypt

\begin{abstract}
Stem cells are undifferentiated cells that remarkable ability to self-renew and produce differentiated cells that support normal development and tissue homeostasis. The authors isolated spherical stem cells from the midgut epithelium of the late third larval instars of Culex pipiens mosquitoes. In vitro, cultivated epithelial stem cells were able to proliferate and differentiate in fresh culture for $48 \mathrm{hr}$ in absence of 20- hydroxyecdysone (20-E). The stem cells were the most common cells in the initial culture. One hundred of epithelial stem cells had been cultured. After $24 \mathrm{hr}$ became 132 cells, $78 \%$ was undifferentiated stem cells and $8.3 \% \& 13.7 \%$ was enterocytes and goblet cells respectively. This ratio slightly decreased after de $48 \mathrm{hr}$ to be $74 \%$ undifferentiated stem cells, $4.5 \%$ enterocytes and 5.6 $\%$ goblet cells. After $72 \mathrm{hr}$ the undifferentiated stem cells were not able to proliferate .The most differentiated goblet and enterocytes survived few days then died.
\end{abstract}

Keywords: Midgut, Stem cells, Tissue culture, Mosquitoes.

\section{Introduction}

Culex (Culex) pipiens L. 1758 (Diptera: Culicidae), the northern house mosquito, is a common pest in urban and suburban areas and one of the most widely distributed mosquitoes in the world (Vinogradova, 2000). The recent spread of West Nile virus has focused attention on this mosquito, which is considered one of the principal vectors of the disease (Turell et al, 2001). Culex pipiens is also a vector of St Louis encephalitis (Beaty and Marquardt, 1996), Japanese encephalitis viruses (Weng et al, 2000), Rift Valley fever (Turell et al, 1996) and banchrofti Filariasis (Soliman, 1995). Understanding vector-pathogen interaction is fundamen-tal to the development of disease control strategies.

The mosquito midgut epithelium is a simple monolayer of polarized columnar epithelial cells throughout which other cell types are occasionally interspersed (Billingsley, 1990). Although the cellular composition of the midgut epithelium is currently controversial (Shahabuddin, 2002), probably only three morphologically distinct cell types are present: columnar epithelial cells (enterocytes), endocrine cells and regenerative cells (Baton and RanfordCartwright, 2004, 2005). Regenerative cells are small pyramidally shaped cells sparsely scattered throughout the basal region of the midgut epithelium, between adjacent midgut epithelial cells, which terminate within the basal half of the midgut epithelium (Hecker et al, 1971; Hecker, 1977). By analogy to morphologically similar cells found in the midguts of other insects, regenerative cells are presumed to be a population of undifferentiated precursor stem cells capable of proliferating and developing into functionally mature midgut epithelial cells (Hecker et al, 1971). However, despite their nominal description, the function of socalled "regenerative"' cells are unproven: no evidence has previously been published that these cells are mitotically active within the midgut epithelium of mature adult female mosquitoes (Hecker et al, 1971; Hecker, 1977; Weaver and Scott, 1990).

In case of most insect lines, cell cycle parameters have not been systematically 
examined. An exception is the Drosophila $\mathrm{KC}$ cells, which have a generation time of about 19 h. In KC cells, G2 was the longest phase of the cell cycle while G1 was short (Dolfini et al, 1970). In contrast, in Aedes albopictus C7-10 cells, G1 was the longest cell cycle phase (duplicated) after low dose $\left(10^{-6} \mathrm{M}\right)$ treatment with 20-E. Overall proliferation of C7-10 cells was inhibited (Gerenday and Fallon, 1996). Using flow cytometr, they verified that over a 20 hour period a decrease in the number of the proportion of cells in $\mathrm{S}$ within 4-6 after exposure to $20 \mathrm{E}$, a transient increase in G2 was followed by the accumulation of more than $70 \%$ of the cell in the G1, consistent with the decrease in the proportion of cells in S and G2 (Gerenday and Fallon, 2004).

Jiang and Edgar (2009) provide evidence that adult midgut precursor (stem) cells in larval Dr. melanogaster are stimulated to proliferate by an epidermal growth factor receptor (EGFR) signaling pathway. In the early larval instars, the surrounding midgut visceral muscles produce the protein Vein, a weak EGFR ligand, which stimulates a low level of adult midgut precursor cell proliferation via a paracrine pathway. Subsequently, two other ligands, Spitz and Keren, are synthesized by the stem cells themselves; these provide autocrine signals that augment the paracrine signal. The combination of signals leads to a higher level of proliferation in the late larval period.

The present approach was based on the ultra structural observations had been made by Baldwin and Hakim (1991). They stated that stem cells are not attached to other cells by separate junctions and that they rapidly proliferate to become the major cell type in the midgut early in the molt. In contrast, mature goblet and the enterocytes remained anchored to one another by separate junctions at this time. So when pieces of midgut from pharate fourth-stage larvae were cultured in vitro for approximately one week, stem, goblet and columnar epithelial cells tended to fall away from the muscle and tracheal framework to lie in a random distribution on the bottom of the culture vessel. In mixed culture, in the presence of the insect molting hormone 20-E and of growth factors generated by cocultured fat body, stem cells in the culture entered mitosis and differentiated into new columnar and goblet cells (Sadrud-Din et al, 1994; Loeb, 1994).

This study aimed to describe isolation and culture of stem cells from the midgut of $C x$. pipiens. Also, to investigate if the midgut stem cell can multiplicate in vitro in absence of 20-E and soluble fat body factors.

\section{Material and Methods}

Mosquito sample collection: $C x$. pipines Mosquito samples were obtained from breeding habitat in Suez Governorate. Mosquito larvae were collected by sampling from various larval habitats and reared in sectary to obtain adults for morphological identification using taxonomic keys (Gad, 1963; Harbach, 1985).

Insect dissection: Before Dissecting the third larval instars, bench sterilized by soap, ethanol, \& sodium hypochlorite and the larvae surface sterilized by immersing $2 \mathrm{~min}$ each in aqueous solutions of $20 \%$ detergent (Tween, Promega) and 0.1\% p-hydrobenzoic acid methyl ester (Sigma, St Louis, MO). Third Larval instars were then transferred to the sterile water and dissected (Fig.1) immediately (Sadrud-Din et al, 1996).

Cells isolation: Midguts were isolated from larvae using the dissecting solution $(\mathrm{NaCl}$ $130 \mathrm{mM}, \mathrm{KCl} 4.7 \mathrm{mM}$, and $\mathrm{CaCl} 21.9 \mathrm{mM}$, $\mathrm{pH}$ 7.2) by means of pins, the end of the abdomen removed. The midgut remains attached to the head and can be cut and allowed to fall into a dish. If the peritrophic membrane protrudes from one end, it can be pulled out with contents. The guts twice rinsed with dissecting solution and LPS ( $\mathrm{NaCl} 178 \mathrm{mM}, \mathrm{KCl} 4.3 \mathrm{mM}, \mathrm{CaCl} 24.3$ $\mathrm{mM}, \mathrm{NaHCO} 33.8 \mathrm{mM}, 0.5 \%$ gentamicin, $0.01 \%$ antibiotic-antimycotic solution, $\mathrm{pH}$ 6.5). The midguts placed in a plastic dish 
(50-mm diameter) filled with LPS after cutting into small pieces then stirring once and then let sit 2-10min. Midguts transferred to another dish and let sit 2$3 \mathrm{~min}$, the same step repeated again. The midgut epithelium does not adhere to the plastic bottom of tissue culture dishes. Consequently, adherent cells such as muscle or Phagocytes are left behind when cells are transferred from one dish to the next. Stem and mature cells generally lie immediately above the bottom of the base of the dishes, then added $70-\mu \mathrm{m}$-pore-size filter basket in 50-mm Petri dish and filled half way with LPS, then midgut added and stirred for 1-2 $\mathrm{h}$ on an orbital or rotating stirrer.

Cell cultivation: The filter basket removed from the Petri dish, placed in media and freed cells into sterile conical bottom test tubes, then centrifuged at $400 \times \mathrm{g}$ for $10 \mathrm{~min}$. Decant LPS, washed with 1-ml fresh LPS, stirred tube to distributed cells in LPS, and then centrifuged again. Repeated, but this step for the second time and used fresh growth medium in absence of $20-\mathrm{E}$ and the growth factor generated by co-cultured fat body. By gentle manual swirling of the plate every 15 min over a 45-60 min period, loosely associated stem cells were liberated into the medium. The gentler the swirling, the fewer non-stem cells were released. Non-stem cells comprised less than $0.5 \%$ of the free cells observed after this process. Intact tissue fragments were then removed from each well using forceps. Free cells were centrifuged at $400 \mathrm{~g}$ for $5 \mathrm{~min}$ and, after removing the supernatants, cells were resuspended in approximately $10 \mathrm{ml}$ of culture medium and distributed evenly into the several wells used in each experiment. The final volume of culture was $500 \mu 1$. Cultures were incubated at $25^{\circ} \mathrm{C}$ in an air environment, and counted at zero time and $24 \mathrm{~h}$ intervals using inverted microscope (Sadrud-Din et al, 1996).

\section{Results}

The media that have been developed was good and allowed us to isolate the stem cells from the midgut epithelium of the $C x$. pipiens mosquitoes. The midgut stem cells were able to proliferate and differentiate to enterocytes and goblet cells, which closely approximate these same processes in vivo (Fig. 2). Conditioned growth medium was not used, 20-E or fat body growth factor. One hundred undifferentiated stem cells cultured in a fresh growth medium were to investigate if factors released from the midgut tissue fragments would be enough to proliferate and differentiate these cells. The authors' knowledge of stem cell functions and controls also derived from studies of stem cells systems in cultures in vitro (Hakim et al, 2010) and Transmission Electron Microscope examination of the midgut epithelium (in vivo) of the third larval instars of $C x$. pipiens (Wassim et al, 2014 in press). After $24 \mathrm{~h}$ the same culture was containing 132 cells, 103 were undifferentiated stem cells as well as differentiated 11 enterocytes and 18 goblet cells. This meant that proliferation of 100 stem cells proceeded quickly through the first $24 \mathrm{~h}$ with division rate $35 \%$. The total no. of proliferated stem cells became $8.3 \%$ enterocytes and $13.7 \%$ was goblet cells. After the second $24 \mathrm{~h}$, the proliferation and differentiation of stem cells of the culture slightly decreased to be $4.5 \%$ enterocytes and 5.6\% goblet cells (table 1). Proliferation of stem cells proceeded very slowly after 72 $\mathrm{h}$. The percentage of differentiated each type of the proliferated and differentiated cells was zero. The differentiated enterocytes and goblet cells survived a few days then died. Undifferentiated stem cells fluctuated between $74 \%$ and $78 \%$ of the total no. of cells and approximately equal the primary cultivated stem cells numbers (Tab.1).

Larval enterocytes and goblet cells cultured in vitro recognized by their morphological similarity to their counterparts in vivo (Fig. 2). The goblet cells are elongate cells with a large central vacuole. The goblet cells have a characteristic pear shape that 
permits their identification. The enterocytes have a brush border at its apical surface and in folded plasma membrane at its base. In midgut, the stem cells lie among the bases of the goblet cells and enterocytes and above the basal lamina. They are not tightly bound to the goblet or enterocytes with mechanical

Table 1: Investigating, counting and differentiating of isolated cells from midgut of Culex pipiens larvae during different time interval

\begin{tabular}{|c|c|c|c|c|c|c|}
\hline \multirow{2}{*}{ Time interval } & \multirow{3}{*}{$\begin{array}{l}\text { Total } \\
\text { \# of } \\
\text { cells }\end{array}$} & \multicolumn{5}{|c|}{ Type and numbers and $\%$ of total isolated Cells } \\
\hline & & \multicolumn{3}{|c|}{ Stem cells } & Columnar cells & Goblet cells \\
\hline Post Cultivation & & Total \# of stem Cells & *D. stem Cell \# & Und. Stem Cell \# & Columnar Cell \# & Goblet Cell \# \\
\hline $24 \mathrm{~h}$ & 132 & $103(78 \%)$ & - & $103(78 \%)$ & $11(8.3 \%)$ & $18(13.7 \%)$ \\
\hline $48 \mathrm{~h}$ & 178 & $160(89.88 \%)$ & $27(15.17 \%)$ & $133(74.73 \%)$ & $8(4.5 \%)$ & $10(5.6 \%)$ \\
\hline $72 \mathrm{~h}$ & 150 & $150(100 \%)$ & $81(54 \%)$ & $69(46 \%)$ & - & - \\
\hline $96 \mathrm{~h}$ & 13 & $13(100 \%)$ & $13(100 \%)$ & - & - & - \\
\hline 1 week & 71 & $71(100 \%)$ & $61(85.9 \%)$ & $10(14.1 \%)$ & - & - \\
\hline
\end{tabular}

\section{Discussion}

The midgut, the second largest organ in the insect body, is the entry site for harmful bacteria, viruses, and toxins, as well as for food and water. This organ consists of a simple or pseudostratified epithelium, which is supported by a basement membrane, striated muscle, and tracheoles. For holometabolous insects, the structure and function of the midgut vary by stage of development. Growth, development and cell death are coordinated by endocrine and paracrine controls. Understanding of these processes and their implications for insect biocontrol is essential (Hakim et al, 2010). Stem cells are responsible for mid gut growth and development and cell death are coordinated by Paracrine and endocrine. The cell contact -based regulation of stem cell activity determines how much growth and differentiation can occur. There are unipotent stem cells exhibit limited capabilities to the formation of one cell type. Stem cell of the insect mid gut give rise to larval goblet and enterocytes when grown in larval culture conditions (Loeb and Hakim, 1996). The results showed that cultures enriched to approximately stem cells gave rise to few mature goblet cells $8 \%$ and enterocytes $13.7 \%$. Spread out cells was the strength. The stem cells are spherical in shape and have central nuclei. The stem cells are the most common cells in the initial culture (Fig. 2). The most differentiated goblet and enterocytes survived few days then died. Other remained as stem cells. earliest indication of differentiation of either cell type. The presence of spherical cells with a neck region preceded the appearance of a mature goblet cell.

The ratio of undifferentiated stem cells remained approximately constant through the $48 \mathrm{~h}$ post cultivation. The results agreed with Morrison et al. (1977) who explained that stem cell function as a reservoir of cells usable for growth or repair where large numbers of cells need to be generated quickly a "symatric" pattern of growth occurs in which stem cells divided into two daughters. Both of which can then divided. In this growth process, the stem cell number increases geometrically. The number of cell produced is two. At the other extreme is an asympatric pattern of cell division where after each division one daughter begins the bath toward differentiation and the other remains a dividing stem cell. In this developmental scheme the number of the stem cells remains the same. Another explanation for the constant ratio of cultivated stem cells is the growth factors released from the tissue fragments conditioned the growth medium. These factors were required for proliferation and differentiation of the cultivated stem cells. Stem cells, detached from the tissue 
fragments, began to proliferate and differentiate into new goblet and enterocytes. Baton and Ranford-Cartwright (2007) verified that in case of injuring the midgut epithelium, enterocytes rupture, releasing its contents though an apocrine process. These secreted contents include cell organelles and the growth factors. At the same time, the midgut stem cells proliferate to replace the damaged cells. If few midgut enterocytes die, the midgut can heal and a new enterocytes formed in vivo.

However, the present study did not use $20-\mathrm{E}$ and the growth factor, the midgut epithelial stem cells were able to proliferate and differentiate in vitro. Our results came together with Gerenday and Fallon (2004) who revealed that the 20-E has no effect on the growth of plated cell line C7-10 from Ae. albopictus after $24 \mathrm{~h}$.The no. of treated cell line with 20 -E $\left(10^{-6} \mathrm{M}\right)$ depressed after 2 days relative to controls. Previous studies (Gerenday and Fallon, 1996) using autoradiography showed that by $10-12 \mathrm{~h}$ after treatment with $20 \mathrm{E}$, the percentage of cells in the $\mathrm{S}$ phase of the cycle decreased sharply. Gerenday and Fallon (2004) verified these observations using flow cytometry. Cells under various treatments were collected from suspension cultures at 2 $\mathrm{h}$ intervals for $20 \mathrm{~h}$, fixed, and processed for flow cytometry as the G1 and G2 peaks decreases noticeably in the 20E-treated cells, relative to controls. In control cells, $\mathrm{S}$ was maintained at a steady level of approximately $40 \%$ and G1 was maintained at about $50 \%$. The remaining approximately $10 \%$ of the cells were in $\mathrm{G} 2 / \mathrm{M}$. The proportion of cells in S declined sharply within 4-6 h after $20 \mathrm{E}$ treatment and by $7 \mathrm{~h}$ after treatment, the proportion of cells in $\mathrm{G} 2$ showed a transient compensatory increase, suggesting that a proportion of the cells underwent mitosis after exposure to 20E. By $12 \mathrm{~h}$ after $20 \mathrm{E}$ treatment, more than $70 \%$ of the cells were in G1 and only $15 \%$ of the cells were in S. During the next $8 \mathrm{~h}$, we noted little change in the proportion of cells in S and G1. The substantial decline in the proportion of cells in $\mathrm{S}$ by $12-15 \mathrm{~h}$ after $20 \mathrm{E}$ treatments would be associated with a decreases in cyclin A. The progression of the cell cycle is regulated by several proteins, including cyclins, cyclin A- dependent kinases, and kinase inhibitory proteins. Homologous of many of these signaling molecules have been described in Drosophila (Edgar and Lerner, 1996).

In Lepidoptera, larval growth is episodic. Midgut epithelial stem cells rapidly proliferate immediately prior to each molt (Baldwin and Hakim, 1991). They differentiate into enterocytes and goblet cells during the molt while intercalating between polyploidy, the previously matured enterocytes and goblet cells enlarge the midgut. After the last larval molt, insects enter metamorphosis (Baldwin et al, 1996; Hakim et al, 2001). In this new environment, stem cells differentiate into a simple cuboidal epithelium (Hartenstein, 1993; Tettammati et al, 2007; Uwo et al, 2002). Within primary cultures, these events occur simultaneously and result in a semi stable balance between stem cell proliferation, differentiation to goblet, enterocytes and death of these mature cells (Loeb and Hakim, 1996). The mature cells, which possess maturation factors, normally do not die in vivo to release these factors. Rather, other mechanisms for release of these factors must occur (Goto et al, 2001).

The present results approved that the isolated stem cells are mitotic ally active within the midgut epithelium of $C x$. pipiens mosquitoes in vitro and entered mitosis. These stem cells were able to proliferate and differentiate into new enterocytes and goblet cells through $24-48 \mathrm{~h}$ post cultivation in fresh growth medium without using 20-E or fat body growth factor. Hakim et al. (2010) stated that, it is unclear how one can mesh the molecular studies on Dr. melanogaster with studies on Lepidoptera cell cultures. Whereas ecdysteroids and -arylphorin could be driving the gene activations seen in the fly. Paracrine factor released by adjacent 
muscle cells are not present in the primary midgut cultures and have not been studied in culture systems. Furthermore, larval $D r$. melanogaster adult midgut precursor cells do not increase their rate of proliferation prior to each molt (Jiang and Edgar, 2009) as do Lepidoptera. Clearly, more data are needed before a complete picture of the factors controlling stem cell proliferation in the larval midgut. Local-acting growth and differentiation factors have been identified and purified from condition medium CM(Midgut Differentiation Factors, MDF1 and MDF2) and from hemolymph of $L$. dispar (MDF3 and MDF4) (Loeb and Jaffe, 2002; Loeb et al, 1999). They were identified by ability to replace $\mathrm{CM}$ in purified stem cell cultures. Although the site of synthesis of the MDFs has not been identified in vivo, antibodies to MDFs stain larval enterocytes in vivo and in vitro, suggesting molecules with similar epitopes are present in the cells (Goto et al, 2001; Loeb et al, 2004).

\section{Conclusion}

The isolated mid gut epithelial stem cells of $C x$. pipiens are mitotically active in vitro, able to proliferate and differentiate into new enterocytes and goblet cells through 24-48 h post cultivation without using 20 -E or fat body growth factor. Extensive work on cell cycle machinary of the Egyptian mosquito species, which genes are regulating this cycle is ongoing to understand the role of cyclins $\mathrm{A}$ and $\mathrm{B}$ in progression of mosquito cell cycle.

\section{References}

Baldwin, KM, Hakim, RS, 1991: Growth and differentiation of the larval midgut epithelium during molting in the moth, Manduca sexta. Tissue Cell 23:411-22

Baldwin, KM, Hakim, RS, Loeb, MJ, SadrudDin, SY, 1996: Midgut develop-ment. In: Biology of the Insect Midgut, ed. MJ Lehane, PF Billingsley. London: Chap-

man and Hall

Baton, LA, Ranford-Cartwright, LC, 2004: Plasmodium falciparum ookinete invasion of the midgut epithelium of Ano-pheles stephensi is consistent with the Time Bomb model. Parasitol. 129:663-76.

Baton, LA, Ranford-Cartwright, LC, 2005: How do malaria ookinetes cross the mosquito midgut wall? Trends Parasitol. 21: 22-8.

Baton, LA, Ranford-Cartwright, LC, 2007: Morphological evidence for prolifera-tive regeneration of the Anopheles stephensi midgut epithelium following Plasmodium falciparum ookinete invasion. J. Invertebr. Pathol. 96:24454.

Beaty, BJ, Marquardt, WC, 1996: The Biology of Disease Vectors. University Pre-ss of Colorado, Newt.

Billingsley, PF, 1990: The midgut ultrastructure of haematophagous insects. Annu. Rev. Entomol. 35:219-48.

Dolfini, S, Courgeon, AM, Tiepolo, L, 1970: The cell cycle of an established line of Drosophila melanogaster cells in vitro. Experientia 26:1020-1.

Edgar, BA, Lerner, CF, 1996: Develop-mental control of cell cycle regulators: a fly's perspective. Science 274:1646-52.

Gad, AM, 1963: Insects of medical importance. Unpublished lecture notes (in Arabic); Research Institute of Medical Entomology, $\mathrm{MOH}$. Cairo, Egypt.

Gerenday, A, Fallon, AM, 1996: Cell cycle parameters in Aedes albopictus mosquito cells. In-vitro Cell. Dev. Biol. Anim. 32: 307-12.

Gerenday, A, Fallon, AM, 2004: Ecdy-soneinduced accumulation of mosquito cells in the G1 phase of the cell cycle. J Insect Physiol. 50, 9:831-8.

Gordon, JI, 1993: Understanding gastrointestinal epithelial cell biology: lessons from mice with help from worms and flies. Gastroenterology 104, 3:15-324.

Goto, S., Takeda, M, Loeb, MJ, Hakim, R S, 2001: Immunohistochemical detection of a putative insect cytokine, midgut differen-tiation factor 1 (MDF-1) in midgut columnar cells of Heliothis virescens. Invert. Reprod. Dev. 40:117-24.

Hakim, RS, Baldwin, KM, Loeb, M, 2001: The role of stem cells in midgut growth and regeneration. In-vitro Cell Dev. Biol. Anim. 37:338-42.

Hakim, RS, Baldwin, K, Smagghe, G, 2010: Regulation of midgut growth, deve-lopment and metamorphosis. Ann. Rev. Entomol. 55:593608. 
Harbach, RE, 1985: Pictorial keysto the genera of mosquitoes, sub-genera of Culex and the species of Culex (Culex) occurring in southwestern Asia and Egypt,with a note on the subgeneric placement of Culex deserticola (Diptera: Culicidae). J. Mosq. Sys. 17, 2:83-107.

Hartenstein, V, 1993: Atlas of Drosophila Development: Cold Spring Harbor, NY: Cold Spring Harbor` Lab. Press.

Hecker, H, Freyvogel, TA, Briegel, H, Steiger, R, 1971: Ultrastructural differen-tiation of the midgut epithelium in female Aedes aegypti (L.) (Insecta, Diptera) imagines. Acta Trop. 28:80104.

Hecker, H, 1977: Structure and function of midgut epithelial cells in Culicidae mosque-toes (Insecta, Diptera). Cell Tissue Res. 184: 321-41. Illa-Bochaca, I, Montuenga, LM, 2006: The regenerative nidi of the locust midgut as a model to study epithelial cell differentia-tion from stem cells. J. Exp. Biol. 209:2215-23.

Jiang, H, Edgar, BA, 2009: EGFR signa-ling regulates the proliferation of Drosophila adult midgut progenitors. Development 136: 483-93

Loeb, MJ, Hakim, RS, 1996: Insect midgut epithelium in vitro: an insect stem cell syst-em. J. Ins. Physiol. 42:1103-11

Loeb, MJ, Jaffe, H, Gelman, DB, Hakim, RS, 1999: Two polypeptide factors that pro-mote differentiation of insect midgut stem cells in vitro. Arch. Insect Biochem. Physiol. 40:129-40. Loeb, MJ, Jaffe, H, 2002: Peptides that elicit midgut stem cell differentiation iso-lated from chymotryptic digests of hemo-lymph from Lymantria dispar pupae. Arch. Insect Biochem. Physiol. 50:85-96.

Loeb, MJ, Coronel, N, Natsukawa, D, Takeda, M, 2004: Implications for the func-tions of the four known midgut differentia-tion factors: an immunohistologic study of Heliothis virescens midgut. Arch. Insect Biochem. Physiol. 56:7-20.

Micchelli, CA, Perrimon, N, 2006: Eviden- ce that stem cells reside in the adult Droso- phila midgut epithelium. Nature 439:475-79.

Morrison, SJ, Wandycz, AM, Hemmati, HD, Wright, DE, Weissman, IL. 1997: Identification of a lineage of multipotent hematopoietic progenitors. Development 124, 1929-39.

Ohlstein, B, Spradling, A, 2007: Multi-potent Drosophila intestinal stem cells specify daughter cell fates by differential Notch signaling. Science 315:988-92.

Park, MS, Takeda, M, 2008: Starvation suppresses cell proliferation that rebounds after refeeding in the midgut of the American cockroach, Periplaneta america-na. J. Insect Physiol. 54:386-92.

Sadrud, DS, Hakim, RS, Loeb, MJ, 1994: Differentiation of stem cells from the midgut of the insect Manduca sexta, occurs in vitro in the presence of a factor from mature larval midgut cells. In-vitro Cell Dev. Biol. Anim. 30A:106.

Sadrud-Din, SY, Loeb, MJ, Hakim, RS, 1996: In vitro differentiation of isolated stem cells from the midgut of Manduca sexta larvae. J. Exp. Biol. 199:319-25.

Soliman, BA, 1995: Comparative exsheth-ment of microfilariae of Wucheraria ban-crofti in certain mosquito species. J. Egypt. Soc. Parasitol. 25, 1:207-12

Shahabuddin, M, 2002: Do Plasmodium ookinetes invade a specific cell type in mosquito midgut? Trends Parasitol. 18:157-61.

Tettamanti, G, Grimaldi, A, Casartelli, M, Ambrosetti, E, Ponti, B, 2007: Programmed cell death and stem cell differentia-tion are responsible for midgut replacement in Heliothis virescens during prepupalinstar. Cell Tissue Res. 330:345-59.

Turell, MJ, Presley, SM, Gad, AM, Cope, S, Dohm, D, et al, 1996: Vector competence of Egyptian mosquitoes for Rift Valley fever virus. Am. J. Trop. Med. Hyg. 54:136-9.

Turell, J, O'Guinn, MJ, Dohm, DJ, Jones, JW, 2001: Vector competence of North American mosquitoes (Diptera: Culicidae) for West Nile virus. J. Med. Entomol. 38: 130-4.

Uwo, MF, Ui-Tei, K, Park, P, Takeda, M, 2002: Replacement of midgut epithelium in the greater wax moth, Galleria mellonela, during larval-pupal moult. Cell Tissue Res. 308:319-31. Vinogradova, EB, 2000: Culex pipiens pi-

piens Mosquitoes: Taxonomy, Distribution, Ecology, Physiology, Genetics, Applied Importance \& Control. Sofia-Moscow: Pensoft.

Wassim, NM, Soliman, BA, Husien, MI, Metwaly, HG, 2014: The role of epithelial stem cells in fate of peritrophic membrane in Culex pipiens mosquito (Diptera: Culicidae). In Press.

Weaver, SC, Scott, TW, 1990: Peritrophic membrane formation and cellular turnover in the midgut of Culiseta melanura (Diptera: Culicidae). J. Med. Entomol. 27: 864-73. 
Weng, MH, Lien, JC, Lin, CC, Yao, CW, sympatric strain of Japanese encepha-litis 2000: Vector competence of Culex pipiens virus. J. Med. Entomol. 37:780-3. molestus (Diptera: Culicidae) from Taiwan for a

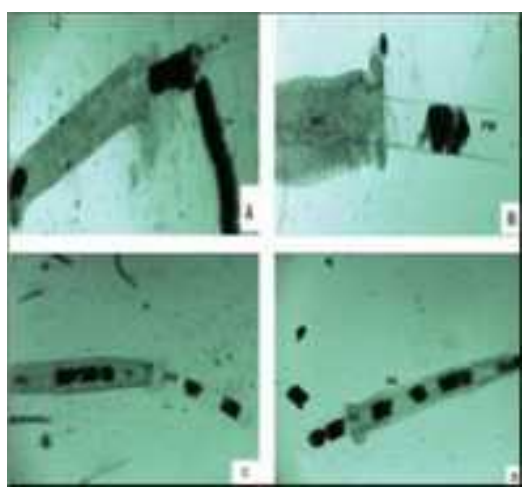

Fig 1: Light micrograph showing mosquito larval midgut dissection

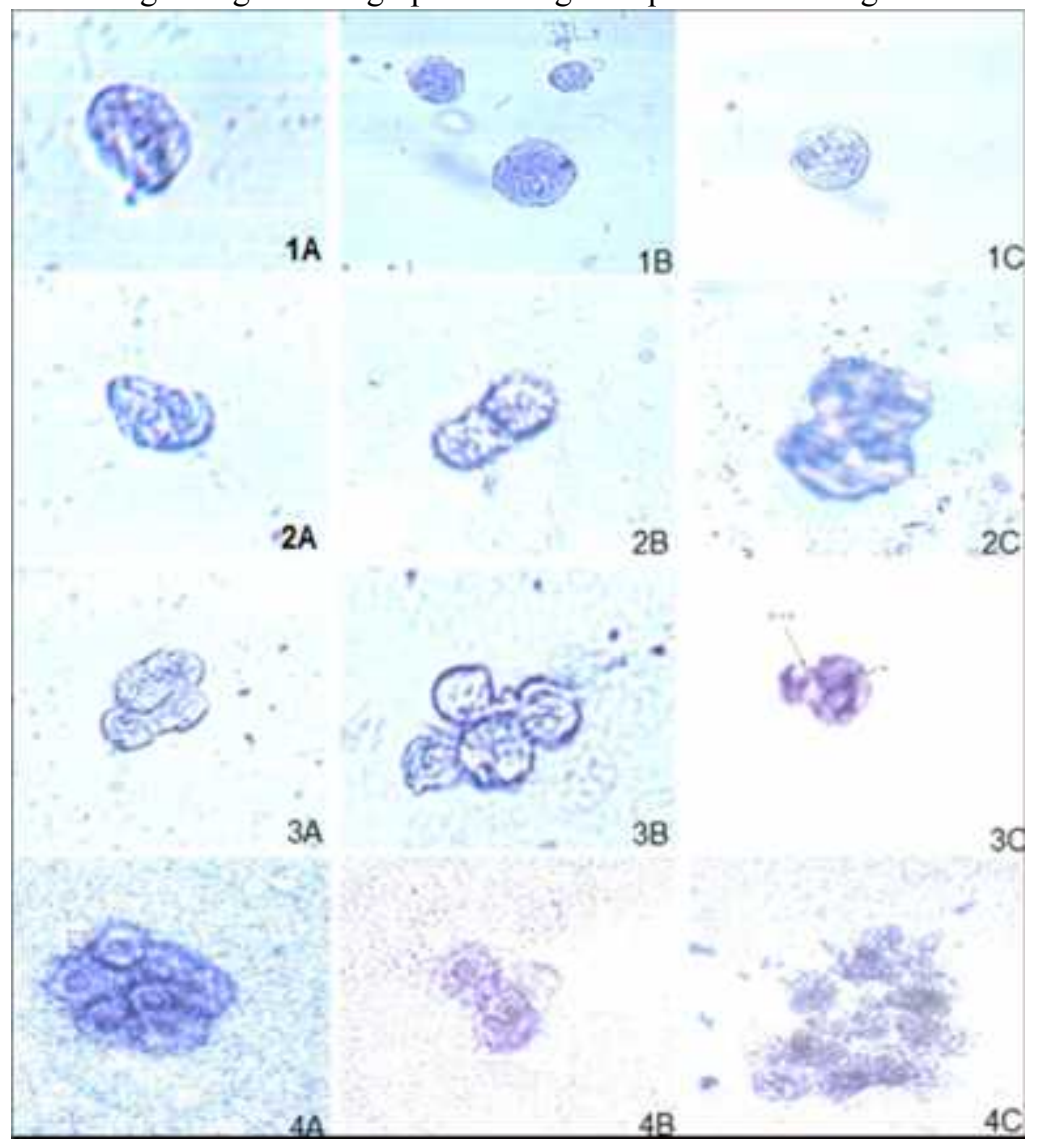

Figure 2: Inverted microscope images of stem cells cultivated from larval $C x$. pipiens midguts $(1 \mathrm{~B}, 1 \mathrm{C})$ at $0 \mathrm{~h},(1 \mathrm{~A}, 2 \mathrm{~A}, 2 \mathrm{~B}, \&$ 2C) 24h. Post cultivation, (3A, 3B, \& 3C) 48h. Post cultivation, (4A, \& 4B) 72hrs. Post cultivation, \& (4C) 168h. Post cultivation. (1A \& 1B 100X, rest 200X).1A: shows different midgut cells (rounded stem cells, columnar cells, pear-shaped goblet cells).1B: shows 3 stem cells (on right solitary cell, on left one stem cell entered division having 2 nuclei and inclusion on membrane, \& last one enlarged stem cell with terminal nucleus). 1C: shows 1 enlarged stem cell with terminal nucleus through division. 2A: shows different midgut cells (stem cells solitary dividing). 2B: shows 1 stem cell (completely divided into 2 cells each with nucleus and membrane attached). 2C: shows 2 stem cells (each entered division, with 2 nuclei included in membrane). 3A: shows 2 stem cells began division (each with 2 nuclei in opposite ends, membrane inclusion increased to separate), 3B: shows cluster of 4 small stem cells ( 2 stem cells divided into 4 cells). $3 \mathrm{C}$ : shows 2 completely stem cells still attached (right one entered another division with 2 nuclei). 4A: shows cluster of 5 stem cells ( 3 with 2 nuclei each in opposite ends and membrane inclusion increased to separate \& 2 cells solitary). 4B: shows 2 stem cells attached together (lower 1 entered division with 2 nuclei and inclusion in membrane). 4C: shows cluster of 8 stem cells. 